\title{
The Use of Blowing Flow Control to Reduce Bluff Body Interaction Noise
}

\author{
D. Angland*, X. Zhang ${ }^{\dagger}$ and M. Goodyer ${ }^{\ddagger}$ \\ University of Southampton, Southampton SO17 1BJ, United Kingdom
}

\begin{abstract}
When an unsteady wake from an upstream body impinges on a downstream body, the resultant interaction noise can be significant. The use of distributed blowing through the surface of a cylinder to reduce this source of noise was investigated in a series of experiments. The two bluff bodies in tandem were a cylinder and an H-beam. Two configurations were tested, one with the cylinder upstream of the H-beam ( $\mathrm{OH}$ configuration) and the other with the H-beam upstream of the cylinder (HO configuration). The default separation distance was $x / \phi=2$. These two configurations modelled the interaction noise due to large perturbations in the wake generated by an upstream component inducing unsteady pressure fluctuations on a downstream component. Blowing was used to break down the large flow structures in the wake and to modify the shear layers. The mean velocities and velocity fluctuations were determined in the flowfield. The application of blowing to the $\mathrm{OH}$ configuration reduced the $u^{\prime} u^{\prime}$ component of the stress term. This resulted in a peak reduction of $9.3 \mathrm{~dB}$ at a Strouhal number of 0.2 . There was a broadband noise reduction of $3.2 \mathrm{~dB}$ averaged over the frequency range $0.05<S t<5$. The effect of blowing on the HO configuration was to inhibit the strong crossflow fluctuations $\left(w^{\prime} w^{\prime}\right)$ between the $\mathbf{H}$ beam and the cylinder by delaying the reattachment of the shear layers onto the surface of the cylinder. This resulted in a large noise reduction of $13.2 \mathrm{~dB}$ at a Strouhal number of 0.8 . There was a broadband noise reduction of $4.3 \mathrm{~dB}$ averaged over the frequency range $0.05<S t<6.3$. The effect of blowing produced additional high frequency noise. This additional noise was minimised with blowing applied through a sintered plate with a very small pore diameter.
\end{abstract}

\section{Nomenclature}

$\begin{array}{ll}A & \text { Blowing area, } \mathrm{m}^{2} \\ C_{p} & \text { Pressure coefficient } \\ C_{\mu} & \text { Blowing coefficient } \\ d & \text { Pore diameter, } \mathrm{m} \\ \dot{q} & \text { Volume flow rate } \mathrm{m}^{3} / \mathrm{s} \\ r & \text { Distance to microphone, } \mathrm{m} \\ S & \text { Reference area, } \mathrm{m}^{2} \\ S_{t} & \text { Strouhal number based on cylinder diameter } \\ s & \text { Component separation distance, } \mathrm{m} \\ T_{i j} & \text { Lighthill stress tensor, } \mathrm{N} / \mathrm{m}^{2} \\ t & \text { Perforated plate thickness, } \mathrm{m} \\ u, v, w & \text { Non-dimensional cartesian components of velocity vector } \\ u^{\prime} u^{\prime}, u^{\prime} v^{\prime}, v^{\prime} v^{\prime} & \text { Non-dimensional components of Reynolds stress tensor } \\ V_{\infty} & \text { Freestream velocity, } \mathrm{m} / \mathrm{s} \\ x, y, z & \text { Cartesian coordinates, } x \text { positive downstream, } y \text { positive to port, } z \text { positive up } \\ x_{s e p} & \text { Distance from separation line in } x \text { direction, } \mathrm{m}\end{array}$

\footnotetext{
${ }^{*}$ Research Fellow, School of Engineering Sciences.

${ }^{\dagger}$ Professor, School of Engineering Sciences. Associate Fellow AIAA.

$\ddagger$ Emeritus Professor, School of Engineering Sciences.
} 


$\begin{array}{ll}\text { Symbols } & \\ \alpha & \text { Porosity } \\ \delta_{\omega} & \text { Non-dimensional shear layer thickness } \\ \phi & \text { Cylinder diameter, m } \\ \psi & \text { Angle to microphone, deg. } \\ \theta & \text { Cylinder angular position, deg. }\end{array}$

\section{Introduction}

IRCRAft landing gears are an important contributor to airframe noise. Indeed airframe noise may be dominated by landing gear noise during approach to landing. ${ }^{1}$ The noise produced by landing gears is broadband in nature. ${ }^{2}$ The typical noise generating mechanism of a landing gear is that of a compact dipole whose strength is proportional to the unsteady force exerted on the fluid by the component. ${ }^{1,2}$ This mechanism is described by Curle's theory. ${ }^{3}$ The directivity of landing gear noise is almost omni-directional at low Strouhal numbers. ${ }^{4}$ At higher Strouhal numbers, the directivity shows more pronounced maxima in the forward and rearward arcs. ${ }^{4}$

Heller and Dobrzynski ${ }^{5}$ stated that wakes from upstream components that interacted with downstream components were significant contributors to the overall noise produced by a landing gear. This study produced interaction noise between two generic bluff bodies, i.e. a cylinder and an H-beam. The two bodies in tandem produced broadband noise. The aim of the study was to reduce this broadband interaction noise with the application of blowing. The simplified, generic components and detailed flow measurements provide an insight into the physical mechanisms responsible for interaction noise.

An unsteady wake that is created by an upstream component generates noise as it impinges on downstream components. It is particularly relevant for geometries involving many bluff body components in a complex configuration where the unsteady wakes impinging on other components is a major source of airframe noise. The interaction noise produced by a turbulent eddy of strength $T_{i j}$ near a compact rigid body is function of the eddy convection velocity $\left(v_{e d d y}\right)$ and the correlation scale $(l)$ of the turbulence. The acoustic power is proportional to the total surface area wetted $\left(S_{w}\right)$ by the turbulent flow. ${ }^{6}$ This is shown schematically in Figure 1. The physical principles behind reducing interaction noise are to reduce the turbulent stresses in the wake, reduce the wake convection velocity that impinges on the downstream component and displacing the wake to prevent or reduce impingement on downstream components. Blowing is a good solution to achieve all of these three depending on where and how it is applied.

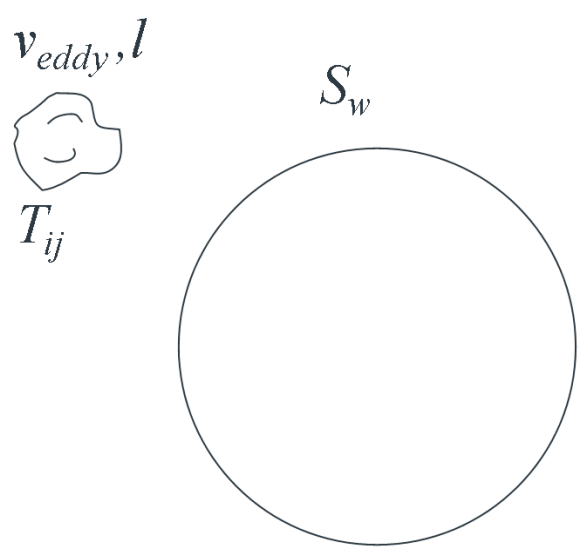

Figure 1. Sound produced by turbulence near a compact rigid body.

Various reviews of flow control for a wide range of applications have been presented by Gad-el-Hak ${ }^{7}$ and more recently Anders et al. ${ }^{8}$ and Bower and Kibens. ${ }^{9}$ Flow control has been used to achieve transition delay, separation postponement, lift enhancement, drag reduction, turbulence augmentation and noise suppression. Jacob et al. ${ }^{10}$ suggested a rod-airfoil configuration as a benchmark problem for broadband noise modelling. Experimental measurements gave the mean flow statistics, instantaneous flow structure and the acoustic field. 
Spectral broadening occurred around the shedding frequency at sub-critical rod diameters due to spanwise randomness. Siller et $a l^{11}$ investigated blowing applied to the leading-edge of an airfoil in the wake of a cylinder. The dominant noise source in that configuration was the impingement of the Karman vortices onto the leading-edge of the airfoil. The Reynolds number of the investigation was between $1 \times 10^{4}$ and $3 \times 10^{4}$. Blowing produced a $7.2 \mathrm{~dB}$ reduction in sound pressure level of the peak measured at the microphone 1.3 $\mathrm{m}$ below the pressure surface of the airfoil. The flow rate used was $\dot{q}=0.0365 \mathrm{~m}^{3} / \mathrm{s}$. Blowing also had the effect of reducing the frequency of the peak slightly. Blowing was useful to reduce the tonal components and redistribute them in the broadband spectrum even though the overall sound pressure level was not reduced.

Fransson et al. ${ }^{12}$ performed an experimental investigation with continuous blowing and suction around a circular cylinder. The Reynolds number in the experiments was subcritical at $10^{4}$. The effect of uniform blowing in their experiments was to promote separation. Drag was shown to increase linearly with blowing rate. The wider wake with blowing resulted in a decrease in Strouhal number proportional to the blowing rate. Mathelin et al. ${ }^{13,14}$ used continuous blowing on the entire surface of a cylinder. The Reynolds number of this investigation was $3.9 \times 10^{3}$. The cylinder had a porosity of $30 \%$ and a pore diameter of $30 \mu \mathrm{m}$. Similar to Fransson's results, blowing resulted in an increase in wake thickness along with a corresponding decrease in Strouhal number. There was an increase in drag of $37 \%$ with blowing.

Blowing has been applied to the trailing-edge of rotor blades to reduce rotor-stator interaction noise. ${ }^{15}$ The noise is tonal in nature and related to the blade passing frequency. Blowing was used to fill the momentum deficit in the wake of the blade. Blowing reduced the Reynolds stresses, vorticity and velocity fluctuations downstream of the rotor. This resulted in a reduction in the tonal interaction noise. ${ }^{15}$

Work has been done on tandem cylinders. Zdravkovich ${ }^{16}$ discussed the flow induced oscillations of two interfering cylinders and the effect of component separation distance $(s / \phi)$. The exact separation distance range is a function of Reynolds number, freestream turbulence and aspect ratio. When the separation distance is close $(s / \phi<1.1)$ the tandem cylinders behave effectively as a single bluff body. Shedding only occurs behind the downwind cylinder. Between a separation distance range of $1.1<s / \phi<1.6$, the shear layer from the upwind cylinder attaches intermittently on the downwind cylinder. At a greater separation distance $(1.6<s / \phi<2.5)$, the shear layers remain attached to the downwind cylinder. Intermittent shedding from the upwind cylinder occurs at $2.5<s / \phi<3.2$. At $3.2<s / \phi<3.8$ the flow is bistable, switching between intermittent shedding and constant shedding behind the upwind cylinder. At large separation distances $(s / \phi>3.8)$, shedding occurs on both cylinders as it would for both cylinders in isolation.

Lockard et al. ${ }^{17}$ compared experimental data of tandem cylinders with a separation distance $(s / \phi)$ of 1.435 to an unsteady Reynolds averaged Navier-Stokes (URANS) solution. The Reynolds number of the investigated was $1.66 \times 10^{5}$ based on the cylinder diameter. At this separation distance there was no strong shedding. The URANS solution produced lower levels of perturbations compared to the experimental results. Lockard et $a l^{17}$ state that the $s / \phi=1.435$ case is likely to be more relevant to real landing gears since no strong vortex shedding occurred. A comparison was also performed at a higher separation distance of $(s / \phi)=3.7 .^{18}$ The primary shedding frequency was determined experimentally to be 0.232 . The unsteady fluctuations measured on the downstream cylinder were $10-15 \mathrm{~dB}$ higher than the upstream cylinder.

Lyn and Rodi ${ }^{19}$ performed experiments on a square cylinder where the separation point is fixed similar to the H-beam used in this investigation. The work focused on the unsteady flapping shear layer close to the body and the similarity behaviour of the average velocities in the shear layer. The streamwise growth of the shear layer was compared to growth laws for unforced mixing layers. The normalised turbulent intensities exhibited systematic deviations from the similarity laws. However, the averaged velocity profiles showed good agreement. Also the shear layer growth rate in the streamwise direction was greater than that predicted by linear growth law of unforced plane mixing layers. The authors concluded that this was possibly due to the effects of recirculation.

Various studies have identified important components on a landing gear that contribute to noise radiated to the farfield. The particular components are dependent on landing gear geometry and component configuration. Lockard et al. ${ }^{20}$ identified gear boxes and wheels to be important noise sources over a large range of frequencies. Lazos ${ }^{21,22}$ stated that the unsteady flow between the inline wheels of a landing gear had the potential to be a significant region of noise generation. This noise source was caused by the the wake of the upstream wheel interacting with the downstream wheel.

Landing gear noise control has primarily focused on the use of fairings and hub caps. ${ }^{23}$ Dobrzynski et al. ${ }^{4}$ performed a series of wind tunnel experiments to determine the effectiveness of add-on devices for landing gear noise reduction on a full scale A340 landing gear. Both nose and main landing gears were tested. The 
add-on devices were removed sequentially to asses their individual effectiveness at reducing landing gear noise. According to Dobrzynski et al. the landing gear noise was generated by flow separation and the consequent interaction of the turbulent wake with downstream gear components. The noise reducing devices included bogie beam undertray, brake fairings, door filler, articulation link cover and wheel caps. For the main landing gear, a broadband noise reduction of 1 to $5 \mathrm{~dB}$, depending on frequency, was obtained with all the devices installed. The use of blowing flow control can be used to deflect flow away from components similar to the fairings, fillers and covers mentioned above. Lockard and Lilley ${ }^{24}$ presented an outlines of technologies to reduce landing gear noise. Methods proposed included shielding the small scale components behind larger ones, fairings to reduce the strong shedding, virtual fluidic fairings and localised blowing to eliminate vortex shedding.

While previous work on blowing flow control has focused on drag reduction or tonal interaction noise reduction, this work investigates controlling broadband interaction noise between bluff body components. An experimental investigation was conducted to determine how the application of blowing to the cylinder modified the aerodynamics and acoustics of the two bluff bodies in tandem. The configurations investigated were an H-beam and a cylinder in tandem, one with the cylinder upstream (denoted by $\mathrm{OH}$ ) and the second with the cylinder downstream of the H-beam (denoted by HO). The two configurations are shown in Figure 2. The advantage of a H-beam was that it produced a broadband spectrum and the separation point did not vary with Reynolds number.

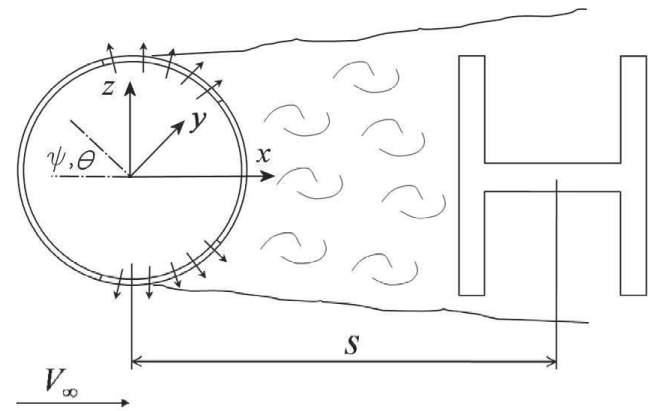

(a) Cylinder upstream of H-beam (OH configuration).

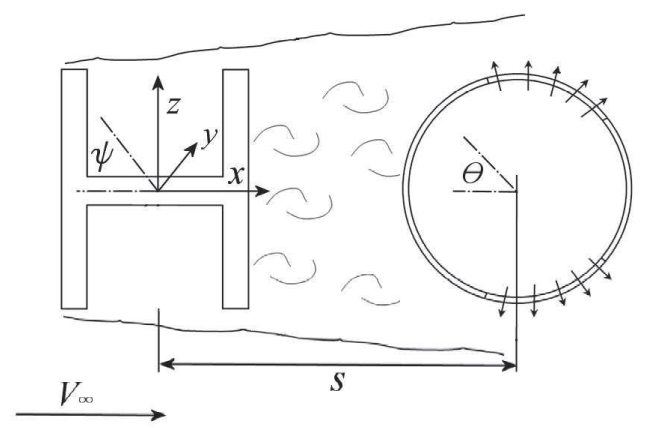

(b) Cylinder downstream of H-beam (HO configuration).

Figure 2. Interaction noise configurations tested.

\section{Apparatus and Procedure}

\section{A. Wind Tunnel}

Particle image velocimetry experiments were conducted in the University of Southampton's low speed $0.9 \mathrm{~m}$ $\times 0.6 \mathrm{~m}$ wind tunnel. The wind tunnel has a closed working section and is of an open circuit design. Perspex endplates were used to achieve a nominally two-dimensional flow around the cylinder and H-beam and to allow optical access. The maximum achievable airspeed was $30 \mathrm{~m} / \mathrm{s}$ with a freestream turbulence level of $0.2 \%$. The blockage ratio was $7 \%$. No blockage corrections were applied to these velocity data.

Free-field acoustic measurements were conducted with an open jet wind tunnel in an anechoic chamber shown in Figure 3. The dimensions of the anechoic chamber were $9.15 \mathrm{~m} \times 9.15 \mathrm{~m} \times 7.32 \mathrm{~m}$. The walls of the anechoic chamber were covered in glass fibre wedges. The lower threshold free-field frequency was $70 \mathrm{~Hz}$. The open jet wind tunnel consisted of a nozzle connected to a series of silencers. The air supplied to the nozzle was from a high pressure air supply at 16 bar. The nozzle had a contraction ratio of 10:1 and the dimensions of the rectangular exit were $0.5 \mathrm{~m} \times 0.35 \mathrm{~m}$. The maximum airspeed was $45 \mathrm{~m} / \mathrm{s}$. Two endplates were mounted at the exit of the nozzle to prevent spreading in the spanwise $(y)$ direction. An arc of 8 microphones was placed over the model. The angle from the model to the microphone was denoted by $\psi$. 


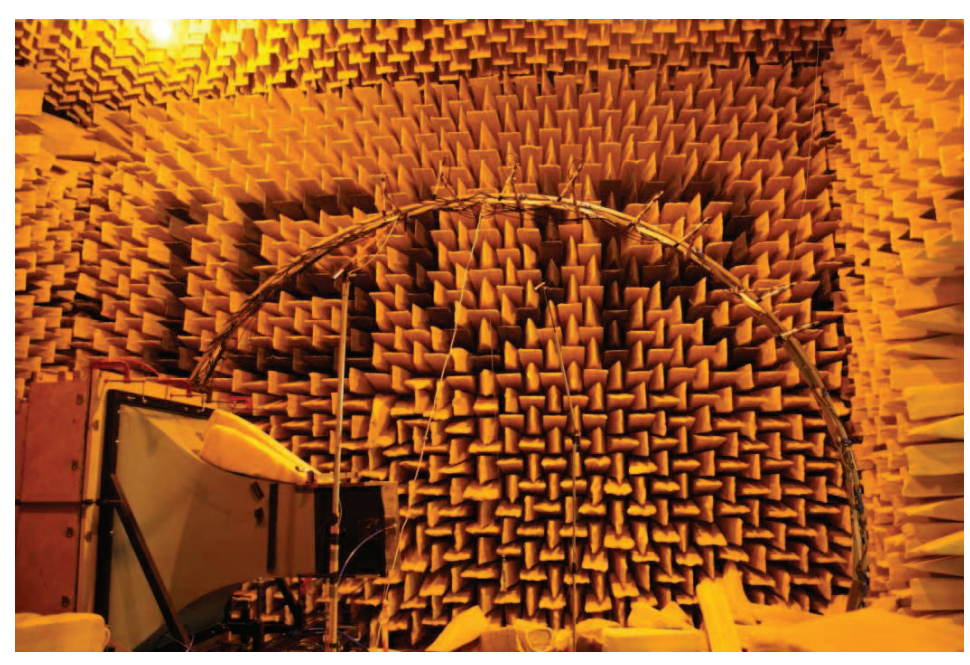

Figure 3. Anechoic open jet facility.

\section{B. Model Design and Blowing System}

A cylinder model was designed to allow distributed blowing to be applied through the surface of the model. The model was made from a carbon fibre cylinder and contained 12 different plenum chambers. The diameter of the cylinder was $0.1 \mathrm{~m}$. The spanwise length of the cylinder was $0.4 \mathrm{~m}$. Endplates were used at the spanwise extremities. The angular positions of the plenum chambers were from 60 to $90 \mathrm{deg}$., 90 to $120 \mathrm{deg}$. and 120 to 150 deg. as shown in Figure 4 on both the upper and lower surfaces. The plenum chambers were further divided at the half-span of the model to give a total of 12 . There were holes on the cylinder surface to allow for the placement of on-surface microphones. The cylinder wind tunnel model is shown in Figure 5. The design of a series of plenum chambers ensured a more uniform distribution of blowing. Blowing was applied to both sides of the cylinder from 60 degrees to 150 degrees as measured from the leading-edge of the cylinder. Each plenum chamber was fed by a cross-drilled pipe.

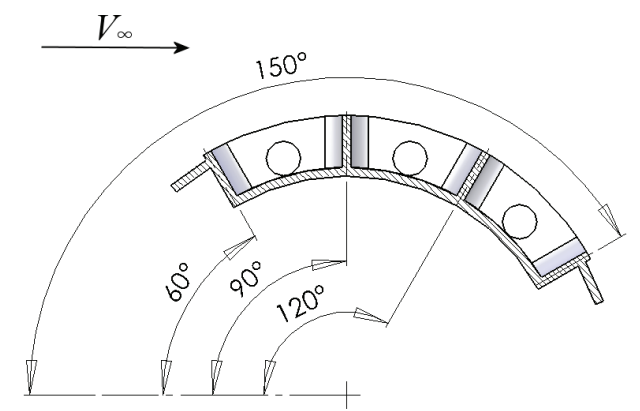

Figure 4. Angular positions of plenum chambers.

The plenum chambers were covered by a permeable plate which allowed air to pass through it. The porosity was kept constant while the pore diameter was changed. Firstly, a perforated steel plate was tested (Plate 1). Secondly, a sintered bronze plate was tested (Plate 2). The sintered plate had a very small pore size and therefore a large pressure loss coefficient, which resulted in less variation in permeation velocity across it. It also resulted in a higher pressure differential across the sintered plate for a given permeation velocity.

The dimensions of the H-beam were $0.1 \mathrm{~m} \times 0.1 \mathrm{~m}$ and it was extruded from aluminium. The default separation distance between the two components $(s)$ was $0.2 \mathrm{~m}(2 \phi)$. The two configurations tested and the definition of the axes are shown in Figure 2. The origin of the spanwise axis $(y)$ was at the mid-span of the 


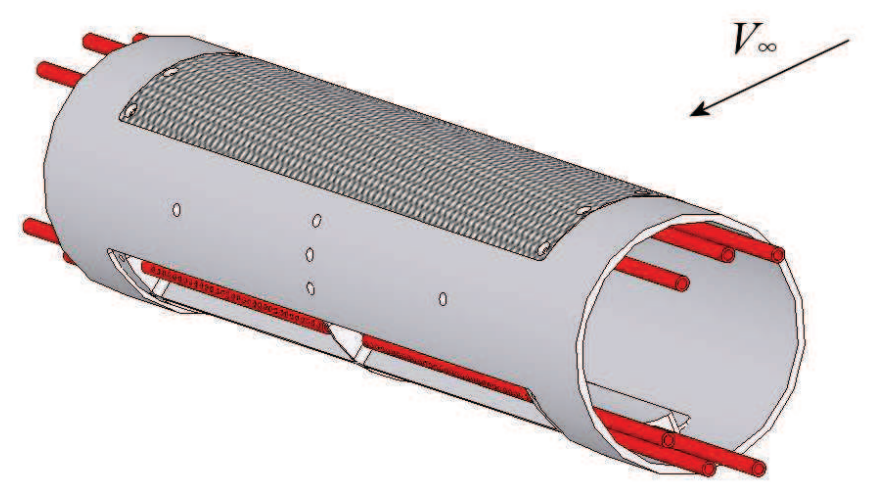

Figure 5. Blowing cylinder model. Lower perforated plate is removed to expose plenum chambers and crossdrilled pipes.

cylinder and H-beam. The Reynolds number of this investigation was between $1.4 \times 10^{5}$ and $2.7 \times 10^{5}$ based on the diameter of the cylinder and the height of the H-beam.

The compressor used to supply the air was a double-flow side channel compressor made by Rietschle. The maximum pressure difference was $\pm 17000 \mathrm{~N} / \mathrm{m}^{2}$. The maximum mass flow rate was $0.078 \mathrm{~kg} / \mathrm{s}$. The blowing pump itself transmitted noise down the delivery pipe. To reduce this additional noise, a settling tank was added to the system. The settling tank consisted of two ducts offset from each other to minimise the direct transmission of sound. It was lined with $12 \mathrm{~mm}$ of open cell foam material to attenuate the noise generated by the pump and transmitted down the pipes. As well as noise attenuation, the settling tank was used to alleviate back pressure problems that were present with the original plumbing configuration. The settling tank dimensions were $0.5 \mathrm{~m} \times 0.5 \mathrm{~m} \times 0.4 \mathrm{~m}$ and it had a volume of 100 litres. A pipe with an internal diameter of $0.038 \mathrm{~m}$ was connected from the compressor pump to the settling tank. Twelve $6 \mathrm{~mm}$ internal diameter pipes were located on the opposite face of the settling tank. These pipes fed the cross-drilled pipes in the plenum chambers as depicted in Figure 5.

\section{Particle Image Velocimetry}

The fluid was seeded with particles typically in the range $1 \mu \mathrm{m}$ to $5 \mu \mathrm{m}$ for the purpose of PIV measurements. The seeding particles in the plane of interest were illuminated with two Gemini Nd:YAG lasers, that were capable of running at $4 \mathrm{~Hz}$, emitting $120 \mathrm{~mJ}$ pulses at $532 \mathrm{~nm}$. The positions of these particles were recorded on a charge-coupled device digital camera at two different times, 15 - $40 \mu$ s apart, depending on airspeed. The typical laser sheet thickness was $2-3 \mathrm{~mm}$.

The laser sheet was shined in a horizontal plane through a perspex window, which made up the port wall of the working section. The camera was attached to a traverse that was mounted above the ceiling of the wind tunnel. The ceiling panel was also made of perspex and allowed optical access to the model in the test section. This allowed $x-z$ planes to be examined. The smoke generator was placed in the same room as the wind tunnel. This ensured the smoke had sufficiently diffused to ensure homogeneity in seeding levels by the time the smoke reached the model in the test section.

An adaptive cross correlation was performed up to a final interrogation area measuring $32 \times 32$ pixels. The horizontal and vertical overlap was $75 \%$. A peak validation of 1.2 was used to reject spurious vectors. The peak validation is the ratio of the first peak in the correlation plane to the second and is a measure of the signal to noise ratio. These time averaged data were averaged over 500 images sampled at $2 \mathrm{~Hz}$. The image size was $175 \mathrm{~mm} \times 140 \mathrm{~mm}$ with a spatial resolution of $1.1 \mathrm{~mm}$ in both directions. The standard error of the mean components of velocity, within $95 \%$ confidence limits, was $\pm 0.0175 \mathrm{~m} / \mathrm{s}$ for 500 samples. 


\section{On-surface Microphone Measurements}

The microphones used for the on-surface measurements were Panasonic WM-60A omnidirectional condenser microphones. These were flush mounted onto the surface of the model. The sensitivity was $-44 \pm 5 \mathrm{~dB}(0$ $\mathrm{dB}=1 \mathrm{~V} / \mathrm{Pa}$ at $1 \mathrm{kHz}$ ). The measurable frequency range was from $20 \mathrm{~Hz}$ to $20 \mathrm{kHz}$. The operating voltage was $2 \mathrm{~V}$ provided by a preamp and the signal to noise ratio was greater than $58 \mathrm{~dB}$. The typical frequency response curve, supplied by the manufacturer, showed that the relative response was constant across the frequency range. The signal from the microphone was sampled at $44.1 \mathrm{kHz}$ for 10 seconds. An FFT was performed with a Hanning window function. The FFT size was 8192 and was averaged over 54 blocks. The frequency resolution of the spectra was $5 \mathrm{~Hz}$.

\section{E. Free-Field Microphones}

The microphone measurements in the anechoic chamber were conducted using eight Behringer ECM8000 microphones mounted on an arc. The frequency response of the microphones was from $15 \mathrm{~Hz}$ to $20 \mathrm{kHz}$. The microphones were powered by a DIGIMAX FS preamplifier. These data were sampled at a frequency of $44.1 \mathrm{kHz}$ with a block size of 8192 averaged over 100 blocks. The frequency resolution of the spectra was $5 \mathrm{~Hz}$. The 8 microphones were spaced equally on the arc from $90 \mathrm{deg}$. to $157 \mathrm{deg}$. measured from the freestream velocity vector.

\section{Results and Discussion}

\section{A. Effect of Component Configuration}

The two configurations tested in the anechoic chamber are shown in Figure 6 with the wind tunnel background noise measured. These acoustic data were averaged over one-third octave frequency bands. The default component separation distance was used $(s / \phi=2)$. The angular position to the free-field microphone $(\psi)$ was $103 \mathrm{deg}$. The non-dimensional distance to the microphone $(r / \phi)$ was 21.4. The Reynolds number of the flow was $2.7 \times 10^{5}$. At low frequencies $(S t<0.1)$ the noise from the model was insufficiently above the background noise for these data to be useful. At high frequencies $(S t>10)$, again the aerodynamically generated sound was close to the background noise. With blowing applied, high frequency noise was generated that was above the background levels. These low frequency data were not used since the signal to noise ratio was too low due to the wind tunnel background noise. These acoustic data were only presented when they were $3 \mathrm{~dB}$ above the wind tunnel background noise. No background noise subtraction was performed.

The microphones were placed outside of the core flow of the open jet wind tunnel. Therefore, the sound waves passed through the shear layer that formed between the jet of the wind tunnel and the ambient air in the anechoic chamber. The effect of the shear layer changed the radiation angle and the amplitude of the sound waves due to refraction due to density gradients in the shear layer. Since no absolute values or directivity are presented and since the primary objective of this work was to determine the change in sound pressure levels, no shear layer refraction corrections were performed.

The spectrum of the $\mathrm{OH}$ configuration was characterised by a broadband peak centered around a Strouhal number of 0.26. A second peak occurred at a Strouhal number of 1.2. The HO configuration was characterised by a lower frequency peak $(S t=0.16)$ due to the wider wake with the H-beam upstream of the cylinder. The wake from the cylinder impinging on the H-beam produced significant interaction noise. This configuration produced more noise than the HO configuration over the frequency range measured.

A grit strip was applied on the upstream cylinder at an angle of $\pm 45 \mathrm{deg}$. for the $\mathrm{OH}$ configuration. The effect of applying a transition strip to the cylinder on the spectra that were measured in the anechoic chamber was negligible at a Reynolds number of $2.7 \times 10^{5}$. Even though the Reynolds number is in the upper subcritical regime, the effect of the H-beam downstream of the cylinder and in such close proximity to the cylinder was to inhibit the strong narrow band vortex shedding that is associated with cylinder flow well into the critical regime. ${ }^{25}$ The spectra that were measured, as shown in Figure 6, showed a broadband peak with no evidence of a strong tone. Also the instantaneous flowfield measured in the particle image velocimetry measured showed an absence of strong coherent vortex shedding in the wake of the cylinder due to the presence of the H-beam. Therefore, the cylinder in the HO configuration did not exhibit the subcritical behaviour it would if it was in isolation. 


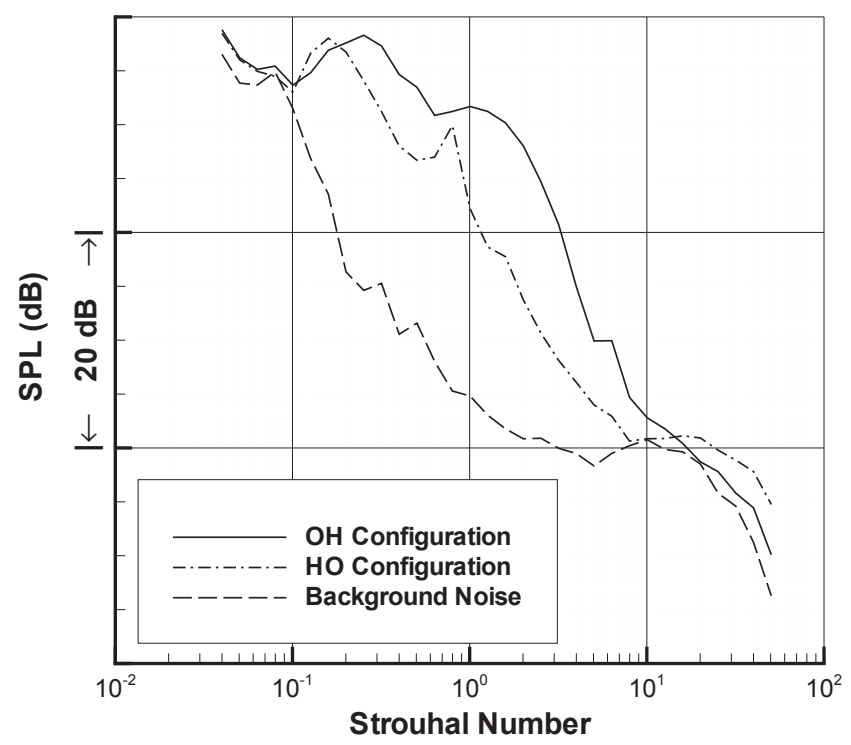

Figure 6. Configuration and wind tunnel noise. $r / \phi=21.4$ and $\psi=103 \mathrm{deg}$.

\section{B. OH Configuration}

\section{Effect of component separation distance}

The effect of the component separation distance on the pressure fluctuations on the downwind face of the cylinder was determined for the $\mathrm{OH}$ configuration in the closed working section $0.9 \mathrm{~m} \times 0.6 \mathrm{~m}$ wind tunnel. An on-surface microphone was placed on the cylinder at $\theta=180 \mathrm{deg}$. measured from freestream velocity vector as shown in Figure 2(a). This corresponded to a position of $(0.5,0,0)$. The root mean squared pressure fluctuations in the wake of the cylinder were subtracted from the values that were measured with an isolated cylinder. The isolated cylinder corresponded to $s / \phi=0$. The results for the wake pressure fluctuations are shown in Figure 7(a) for a Reynolds number of $2.1 \times 10^{5}$. The maximum pressure fluctuations on the downwind face of the cylinder were measured at a separation distance $(s / \phi)$ between 1.5 and 2 between the components. The pressure on the downstream component reduced to a minimum at $s / \phi=3$ but then increased with increasing separation distance as the influence of the downstream component on the cylinder diminished. The default separation distance in these experiments was $s / \phi=2$.

The effect on the shedding frequency of the cylinder is shown in Figure 7(b) as a function of separation distance. The value at $s / \phi=0$ is for the isolated cylinder with no H-beam downstream. As the H-beam was brought close to the upstream cylinder, the frequency of the shedding of the wake increased to a maximum value of a Strouhal number of 0.35. At the default separation distance of $s / \phi=2$, the shedding frequency was at a Strouhal number of 0.276 . The value measured in the anechoic chamber open jet facility was 0.26. The values were within $6 \%$ between the two facilities at the two different Reynolds numbers. As the component frequency separation distance increased further, the influence of the downstream H-beam became increasingly diminished. The Strouhal returned to a value of approximately 0.2 .

\section{Flowfield}

The flowfield for the $\mathrm{OH}$ configuration was investigated using particle image velocimetry. The boundary layer separated from the surface of the cylinder and formed a shear layer and a wake downstream of the cylinder. This shear layer contained the peak Reynolds stresses and was the source of the interaction noise when it impinged on the H-beam downstream. The hardwall results showed the source of the interaction noise and aerodynamic flow features responsible. They also serve as a baseline with which to compare the results with blowing applied. 


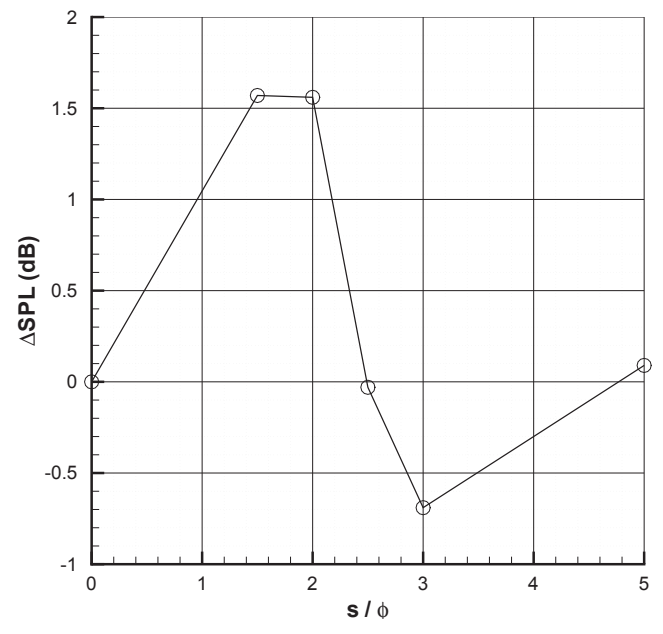

(a) $\triangle S P L$ versus component separation distance.

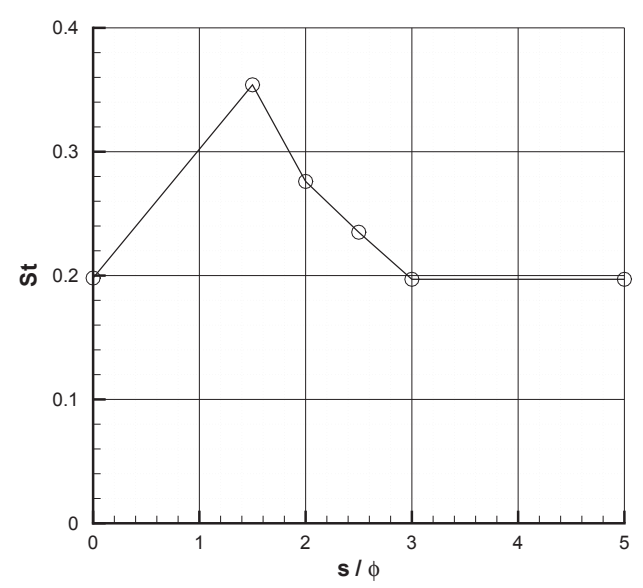

(b) Peak frequency versus component separation distance.

Figure 7. Effect on cylinder downstream surface pressures with component separation distance.

The streamwise velocity $(u)$ profiles are shown in Figure $8(\mathrm{a})$ along the $z$ direction normal to the freestream velocity vector. The velocity components were non-dimensionalised with respect to the freestream velocity. The profiles showed the growth of the shear layer in the proximity of the cylinder surface. The first profile was at a streamwise location of $x / \phi=0$, which corresponded to an angular position $(\theta)$ of 90 deg. This position was very close to the separation line on the cylinder. This was evidenced by a very small region of reversed flow close to the wall $(z / \phi=0.5$ at this streamwise location). There was a steep velocity gradient across the narrow shear layer. At the edge of the shear layer, the flow accelerated beyond the freestream velocity due to the velocity field induced by the cylinder. At a streamwise profile at $x / \phi=0.25$, the area of reversed flow can clearly be seen near the surface of the cylinder. The width of the wake increased in the streamwise direction. At a streamwise profile that was coincident with the downstream face of the cylinder $(x / \phi=0.5)$, the momentum deficit that formed the low pressure wake behind the cylinder is seen. The shear layer was acted upon by diffusion which reduced the gradient in the shear layer and spread the wake aft of the cylinder.

The first derivative of the streamwise velocity $(\partial u / \partial z)$ is shown in Figure $8(\mathrm{~b})$. The gradient of $u$ is important in turbulence modelling where the Reynolds stress tensor is approximated by the product of eddy viscosity and mean strain rate. The Reynolds stresses were non-dimensionalised with respect to $V_{\infty}^{2}$. Comparing the Reynolds stress $\left(u^{\prime} u^{\prime}\right)$ shown in Figure 8(c) with the first derivative of the velocity shown in Figure 8(b), a strong correlation was suggested. This result has been well documented by others including Lyn and Rodi ${ }^{19}$ for a flapping shear layer around a square cylinder. In the region close to the cylinder, the stress term $u^{\prime} u^{\prime}$ dominated over the other stress terms, i.e. $w^{\prime} w^{\prime}$ and $u^{\prime} w^{\prime}$. The gradient $\partial u / \partial z$ was the strongest gradient and the largest contributor to the strain rate tensor. The Reynolds stresses in the shear layer are an indicator of the potential of shear layer as an acoustic source as it impinged on the downstream component.

Profiles of the Reynolds stresses upstream of the H-beam at $x / \phi=1.3$ are shown in Figure $8(\mathrm{~d})$. This was the flowfield that impinged on the H-beam resulting in the interaction noise. The peak stress component was the streamwise component $\left(u^{\prime} u^{\prime}\right)$. The magnitude was 0.19 , which was greater than the value measured immediately in the vicinity of the cylinder at $x / \phi=0.5$. The $z$ location of the peak corresponded to the peak velocity gradient in the shear layer as shown in Figure 8(d). The shear layer was close to the edge of the H-beam $(z / \phi= \pm 0.5)$. Therefore, the peak velocity fluctuations in the wake of the cylinder were close to the downstream H-beam. The peak of the crossflow component $w^{\prime} w^{\prime}$ of the fluctuations was located inboard of the shear layer within the wake. The relatively weak crossflow fluctuations at this downstream profile indicated a lack of strong coherent vortex shedding associated with subcritical cylinders. 


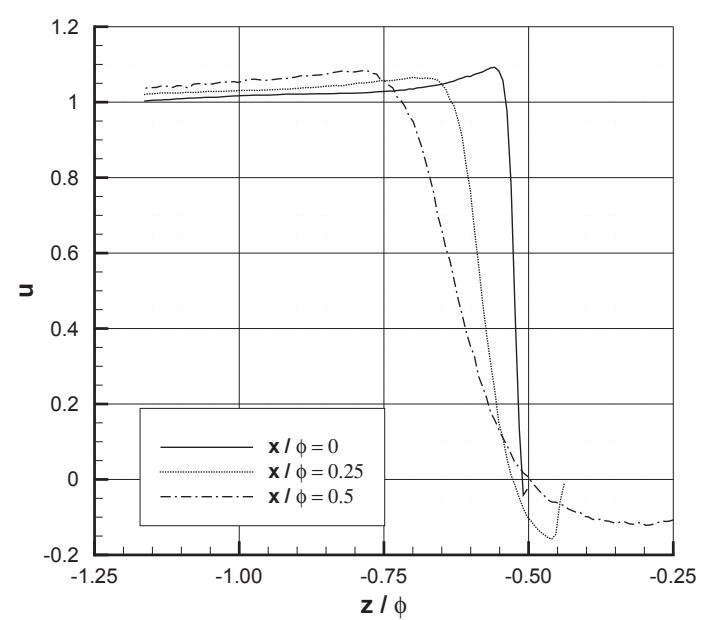

(a) $u$ velocity profiles.

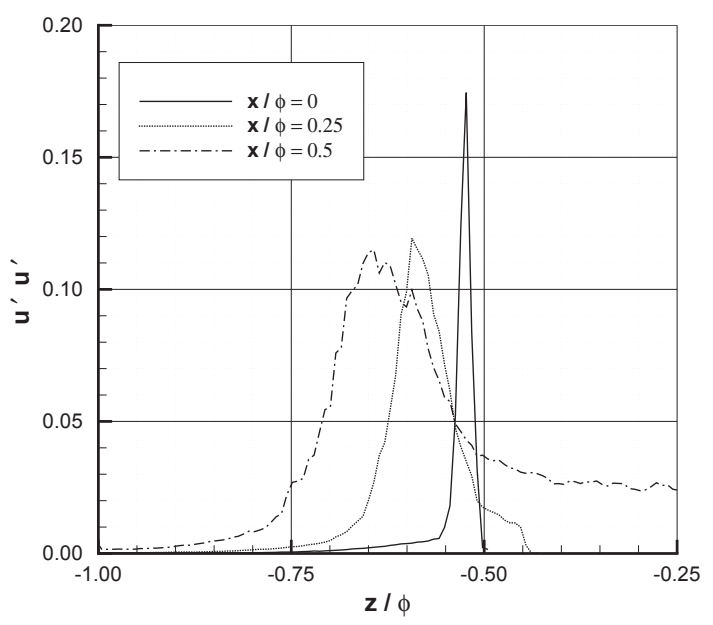

(c) $u^{\prime} u^{\prime}$ profiles

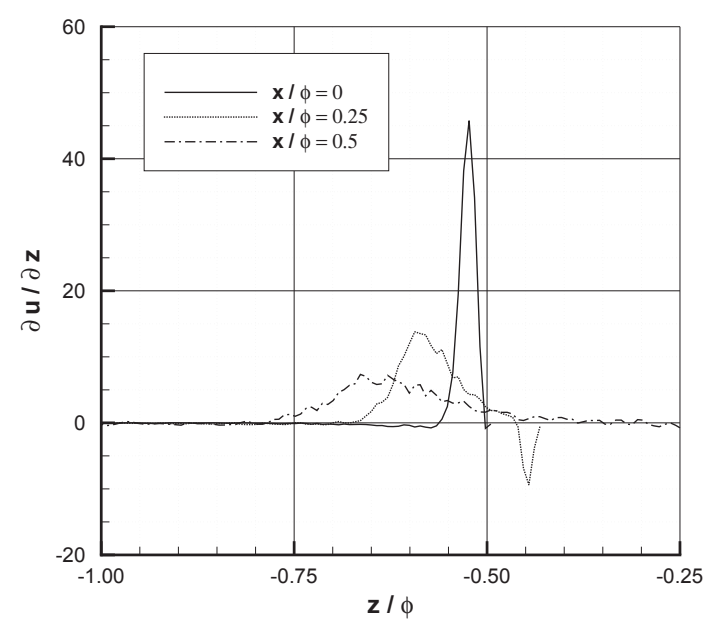

(b) $\partial u / \partial z$ profiles.

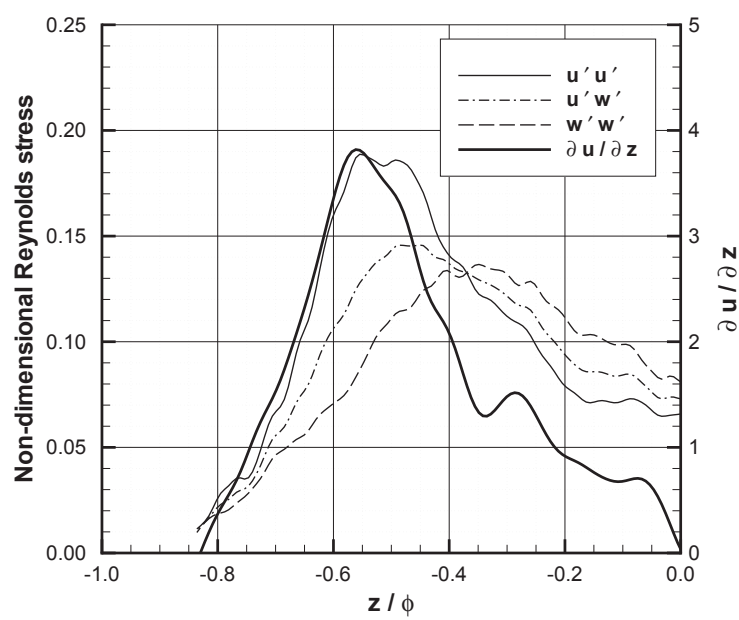

(d) Reynolds stresses upstream of H-beam at $x / \phi=1.3$.

Figure 8. Profiles adjacent to and downstream of cylinder.

\section{Effect of blowing}

The effect of blowing on the aerodynamic flowfield was investigated. The changes in the flowfield were related to changes in noise. The volume flow rate was non-dimensionalised as a blowing coefficient as follows,

$$
C_{\mu}=\frac{\dot{q} V_{i}}{\frac{1}{2} V_{\infty}^{2} S}=\left(\frac{2}{A S}\right)\left(\frac{\dot{q}}{V_{\infty}}\right)^{2},
$$

where $V_{i}$ is the injection velocity. The blowing area $(A)$ was defined as the product of the surface area of the perforated plate and the porosity. The blowing reference area $S$ was equal to the projected frontal area of the cylinder $\left(S=0.04 \mathrm{~m}^{2}\right)$. The form of the equation on the right hand side of Equation 1 is the most useful to determine in these experiments since the terms are easy to measure.

The effect of blowing through the perforated surface of the cylinder is shown with the streamwise velocity profile shown in Figure 9 (a) at $x / \phi=0.25$. For the hardwall case, the flow was reversed close to the surface of the cylinder as the boundary layer had separated. With the application of blowing through the surface of the 
cylinder, at a blowing coefficient of $1.7 \times 10^{-3}$, there was a small jet blowing downstream. This is shown in the inset in Figure 9(a). At $z / \phi=0.46$, which was the point of minimum velocity for the hardwall case close to wall, the streamwise velocity with blowing goes from -0.17 to 0.17 . The effect of this blowing displaced the location of minimum velocity further from the wall but resulted in a narrower wake. The $z$ location of $u_{\max }$ moved inboard from 0.69 to 0.64 . This corresponded to a $5 \%$ reduction in the half-width of the wake. The narrower wake decreased the length scale of the flow structures in the wake of the cylinder. This resulted in reduced Reynolds stresses in the wake and shear layer that impinged on the H-beam downstream of the cylinder.

Examining the Reynolds stresses helped determine how the application of blowing changed the structures in the wake and altered the shear layer. In two dimensional PIV three components of the Reynolds stress tensor can be determined, i.e. $u^{\prime} u^{\prime}, u^{\prime} w^{\prime}$ and $w^{\prime} w^{\prime} . u^{\prime}$ and $w^{\prime}$ are the perturbed velocities about the mean flow. Therefore they are a measure of the magnitude of unsteady velocity fluctuations in the wake. The unsteady wake that impinged on the downstream component is a source of significant additional noise. To reduce the interaction noise the large perturbations in the wake needed to be reduced. The Reynolds stresses at $x / \phi=0.25$ are shown in Figure 9(b). The effect of blowing on the flowfield close to the cylinder surface was to reduce the Reynolds stress slightly. It also reduced the width of the peak due to narrowing of the wake. The blowing interrupted the shedding behind the cylinder as will be seen in the free-field microphone measurements.

Upstream of the H-beam at a streamwise location of $x / \phi=1.3$, the magnitude of the peak stress was approximately halved with the application of blowing as shown in Figure 9(c). The location of the peak stress was also moved towards the centerline. Both of these effects resulted in less noise being generated by the components in interaction.

Due to the modified oncoming flow approaching the H-beam, the flow around it showed changes with the application of blowing. The mean streamwise velocity profile at the side of the H-beam at a streamwise location of $x / \phi=1.75$ showed that the flow around the H-beam was entrained closer to the surface of the H-beam compared to the hardwall baseline case (Figure $9(\mathrm{~d})$ ).

The Reynolds stresses at the side of the H-beam are shown in Figure 9(e). Due to the modified wake of the upstream cylinder, the turbulent stresses in the shear layer around the H-beam were greatly reduced. This resulted in significantly less noise been generated.

The growth of the shear layer thickness $\left(\delta_{\omega}\right)$ is shown in Figure $9(f)$ for both the hardwall and the blowing case. The shear layer thickness is defined as follows,

$$
\delta_{\omega}=\frac{\Delta u_{\max }}{(\partial u / \partial z)_{\max }}
$$

where $\Delta u_{\max }=\left(u_{\max }-u_{\min }\right)$ measured at the extremities of the shear layer. For a steady plane mixing layer, the growth in the streamwise direction is linear. Initially between $0<x_{\text {sep }} / \phi<0.5$ the growth is approximately linear for the hardwall case. Aft of the cylinder surface $\left(x_{\operatorname{sep}} / \phi>0.5\right)$, the growth rate of the shear layer reduced. The origin of the shear layer was the separation point $\left(x_{s e p}=0\right)$. This was estimated from the particle image velocimetry measurements. The linear growth law for bluff-plate flow for an unforced mixing layer ${ }^{26}$ is shown as the dotted line in Figure 9(f). The larger growth of the shear layer for the hardwall case is likely to be due to the recirculating region providing additional mixing to the flow.

The shear layer thickness, as defined in Equation 2, is shown in Figure 9(f) with blowing applied. The growth rate of the shear layer is significantly less than the hardwall case. The decrease in shear layer growth was due to the increase in velocity gradients across the shear layer and the narrowing of the wake with the application of blowing. With the application of blowing, the wake was stabilised behind the cylinder as shown in the Reynolds stresses profiles. This reduced the forcing that acted on the shear layer that caused it to grow rapidly. 


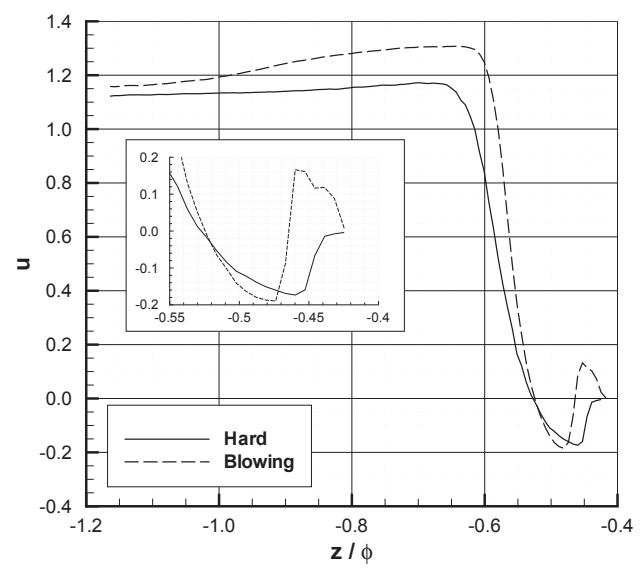

(a) $u$ velocity profiles at $x / \phi=0.25$.

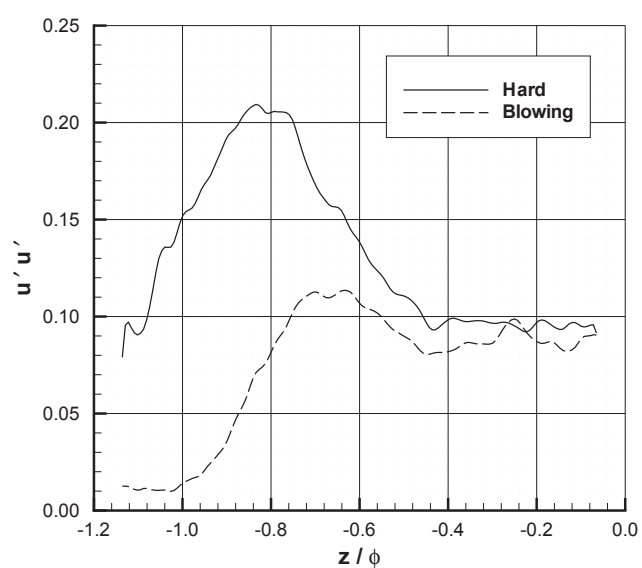

(c) Reynolds stress profiles at $x / \phi=1.3$.

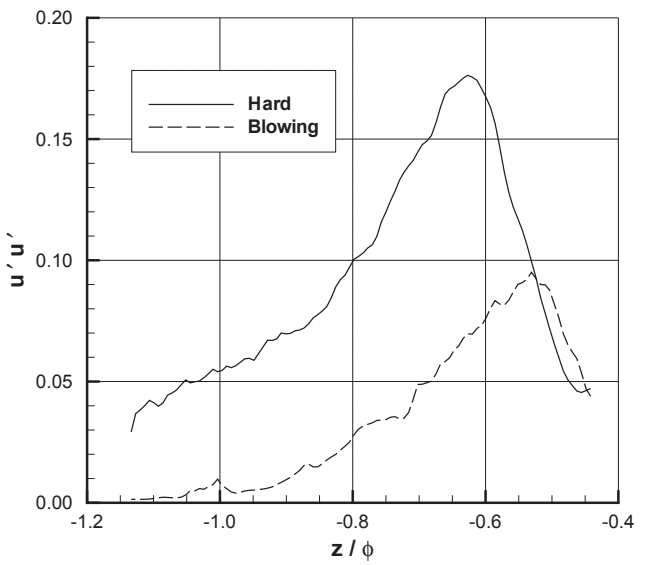

(e) Reynolds stress profiles at $x / \phi=1.75$.

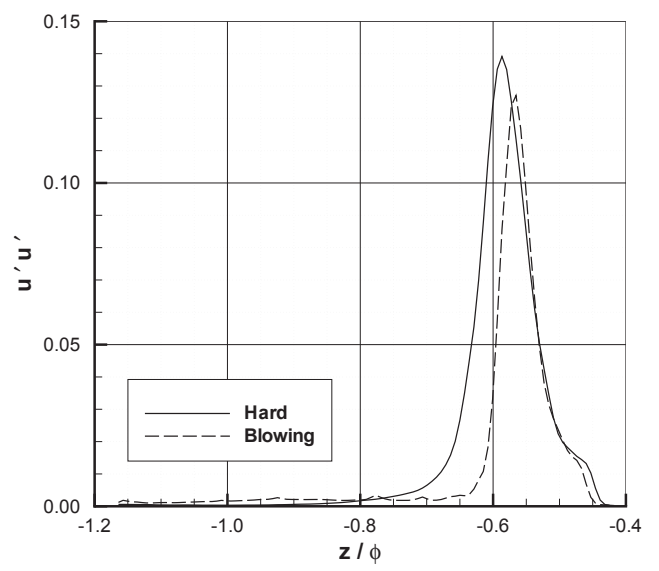

(b) Reynolds stress profile at $x / \phi=0.25$.

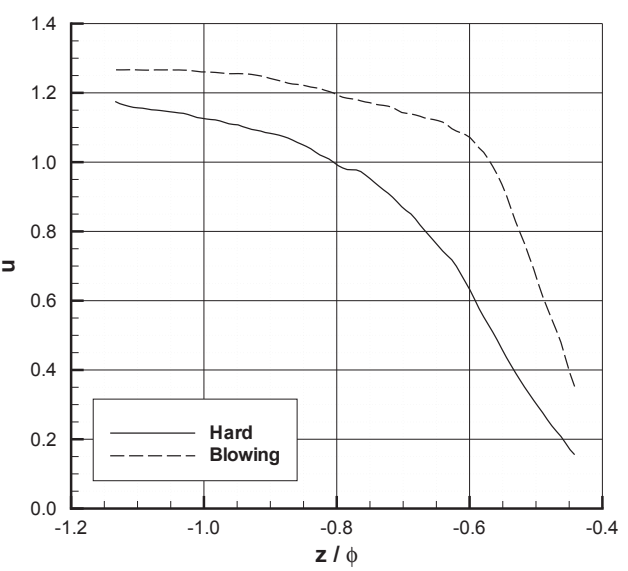

(d) $u$ velocity profiles at $x / \phi=1.75$.

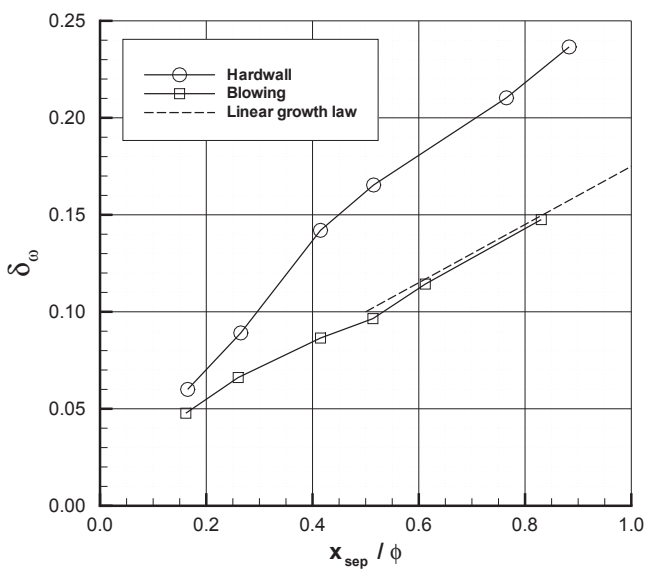

(f) Shear layer thickness with blowing applied.

Figure 9. Profiles with blowing. $C_{\mu}=1.7 \times 10^{-3}$. 
The effect of blowing on the upstream cylinder was to breakdown the large flow structures in the wake which was evidenced by the reduction in the velocity fluctuations in the shear layer and wake. This reduction in wake strength reduced the interaction noise when the turbulent wake impinged on the downstream component. To determine the acoustic reduction, free-field microphone measurements were made in an anechoic chamber.

The advantage of applying blowing on the cylinder is that the pressure on the surface at an angle greater than approximately $30 \mathrm{deg} .{ }^{\mathrm{a}}$ is less than the freestream pressure. The blowing in this experiment was applied from $60 \mathrm{deg}$. to $150 \mathrm{deg}$. where the surface pressure on the cylinder induced flow through the perforated material as well as the pressure supplied by the blowing pump. The higher the freestream velocity $\left(V_{\infty}\right)$, the greater this pressure difference across the perforated plate.

\section{Free-field acoustics}

From the aerodynamic flowfield investigation it was shown that blowing on the cylinder reduced the large velocity fluctuations in the wake due to breaking down the large flow structures in the wake. This modified the wake that impinged on the H-beam downstream resulted in significantly less noise been generated. Spectra with three different flow rates shown are Figure 10(a) with Plate 1 applied. The application of blowing produced reductions in the low frequencies where most of the noise was generated. The peak reduction was $-6.5 \mathrm{~dB}$ at a Strouhal number of 0.202 with a blowing coefficient of $1.7 \times 10^{-3}$. There was also a broadband reduction up to Strouhal number of approximately 7. Above a Strouhal number of 10 a broadband peak that was due to the blowing noise was generated. At $40 \mathrm{~m} / \mathrm{s}$ this corresponded to a frequency of $12.5 \mathrm{kHz}$. At high blowing rates, the noise due to blowing was significant. With Plate 2 applied, the reductions in the broadband noise were greater. The peak reduction was at a blowing coefficient of $1.15 \times 10^{-3}$ and corresponded to $9.3 \mathrm{~dB}$ at a Strouhal number of 0.202 . The sintered plate covered the cross-drilled pipes delivering the air to the plenum chambers. Due to the increased impedance of the material, the blowing noise was significantly less and at a blowing rate of $1.15 \times 10^{-3}$ was barely perceptible above the noise generated by the model.

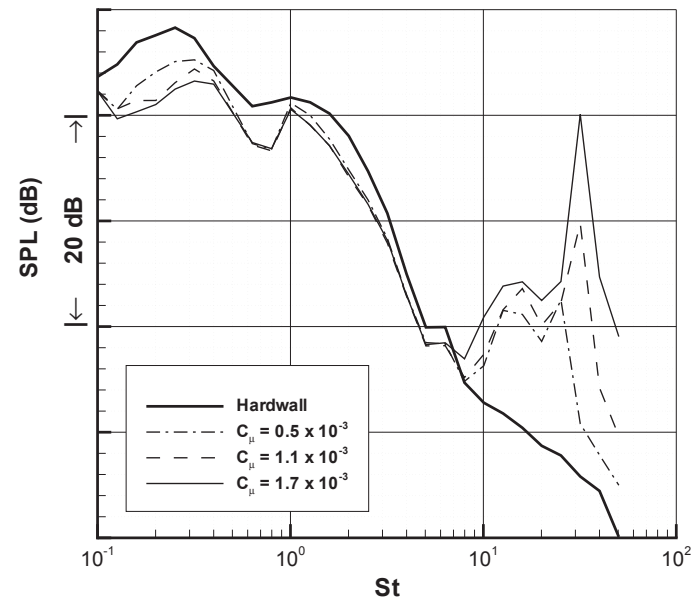

(a) $\mathrm{OH}$ noise with Plate 1.

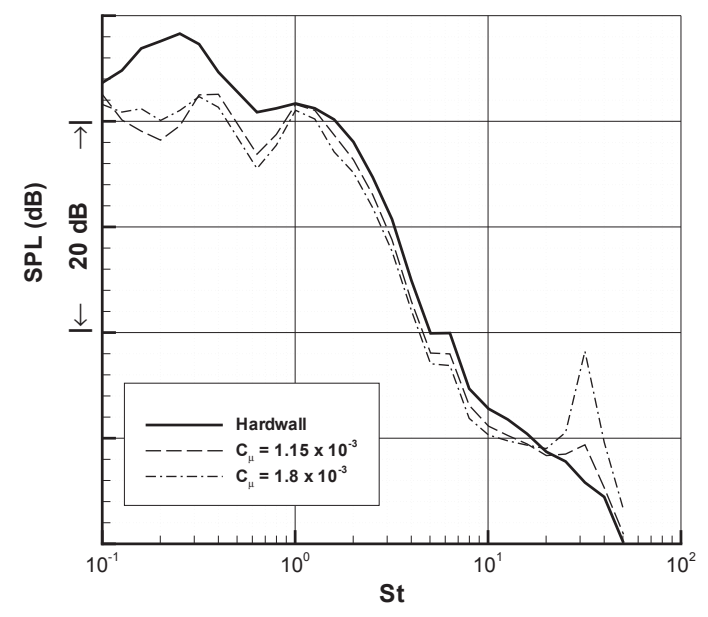

(b) $\mathrm{OH}$ noise Plate 2.

Figure 10. Acoustic measurements. $r / \phi=21.4$ and $\psi=103 \mathrm{deg}$.

The reductions were integrated over certain frequency ranges to show the effect of flow rate on broadband noise reduction. These are shown in Figure 11. The peak reduction was centered around a Strouhal number of 0.2 . The peak reduction did not increase indefinitely with an increase in flow rate. With sufficiently large flow rates additional noise was produced over an increasingly large frequency range. Only relatively moderate flow rates were required to achieve the maximum noise reductions.

\footnotetext{
${ }^{a}$ From potential flow theory, the pressure distribution on a cylinder is given by $C_{p}=1-4 \sin ^{2} \theta$. This can be rewitten to show that $p<p_{\infty}$ when $\theta>30 \mathrm{deg}$.
} 
Plate 2 produced larger reductions over all the frequency ranges. Since Plate 2 had a small pore diameter, this increased the uniformity of the flow across the plate due to the increased resistance and the closeness of the orifices through which the air passed. The effect of this was to stabilise the flow downstream of the cylinder thereby producing less interaction noise. The maximum reductions were achieved with a blowing coefficient of $1.15 \times 10^{-3}$. The average reduction from a Strouhal number of 0.1 to 0.8 was $4.9 \mathrm{~dB}$.

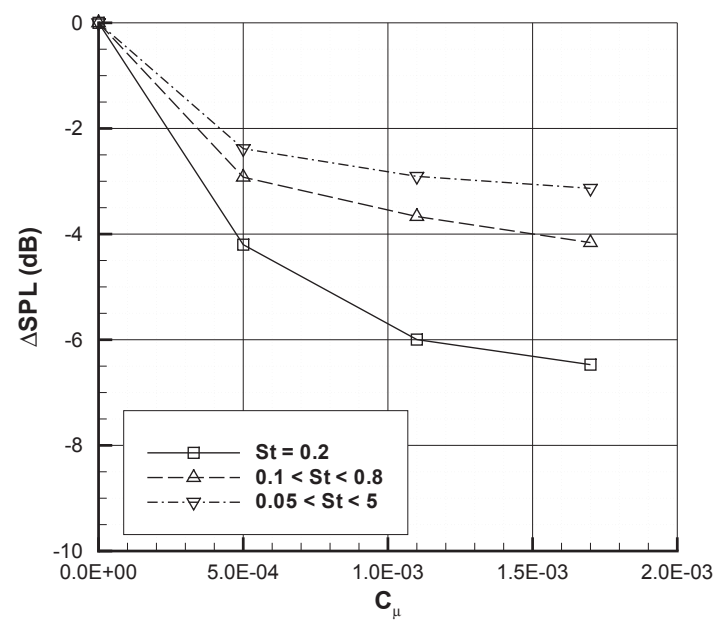

(a) Plate 1.

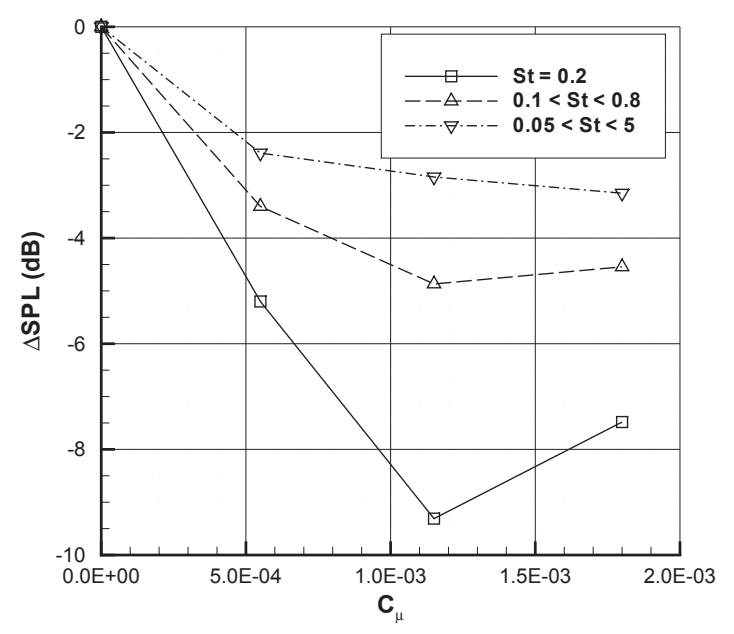

(b) Plate 2.

Figure 11. Integrated noise reductions.

\section{HO Configuration}

\section{Flowfield}

The second configuration tested was the H-beam upstream of the cylinder. This configuration produced less noise than the $\mathrm{OH}$ configuration. The flowfield was investigated using particle image velocimetry to determine the mean flow features and the unsteady velocity perturbations. The wake produced by the $\mathrm{H}-$ beam upstream of the cylinder is shown in Figure 12(a) for profiles from the trailing-edge of the H-beam to the leading-edge of the cylinder. The mean flow was characterised by a large area of recirculating flow between the H-beam and the cylinder as shown in Figure 13(a). The flow reattached on the cylinder at a mean angle of $70 \mathrm{deg}$. The profile at the trailing-edge of the H-beam showed a strong gradient. Under the action of diffusion the gradient across the shear layer is reduced in the streamwise direction.

The three Reynolds stress components are shown in Figures 12(b)-(d). The peak streamwise velocity fluctuations were in the shear layer close to the trailing-edge of the H-beam. In the wake of the H-beam these fluctuations reduced and moved towards the cylinder surface where the shear layer attached. The $w^{\prime} w^{\prime}$ component in the recirculation region $(x / \phi=1)$ was of a similar magnitude to the $u^{\prime} u^{\prime}$ component $(\approx 0.27)$. Close to the surface of the cylinder there were significant crossflow fluctuations as shown in Figure 12(d). At $x / \phi=1.5$ the peak $w^{\prime} w^{\prime}$ fluctuations were 1.2 due to the strong wake aft of the H-beam. For this configuration this Reynolds stress term dominated the stress tensor. These large fluctuations induced a large unsteady flow around the cylinder thereby producing sound.

\section{Effect of blowing}

Blowing was applied from $30 \mathrm{deg}$. to $120 \mathrm{deg}$. on the cylinder. The blowing was most effective when the flow control was applied to this angular position compared to $60 \mathrm{deg}$. to $150 \mathrm{deg}$. and $-45 \mathrm{deg}$. to $45 \mathrm{deg}$. The effect on the nearfield mean flowfield and on the velocity fluctuations are presented. The changes in the aerodynamic flowfield are related to the changes in sound pressure level that were measured in the anechoic chamber. The effect of blowing was to move the reattachment point of the shear layer downstream on the 


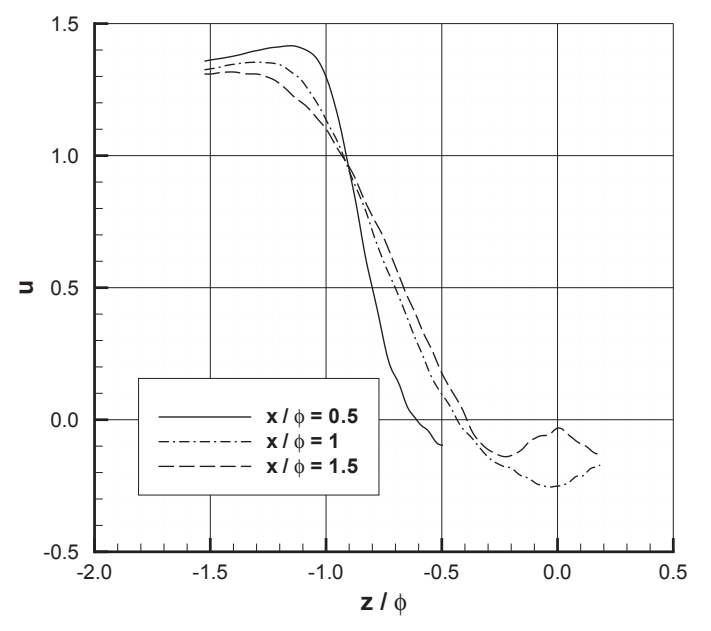

(a) $u$ velocity profiles.

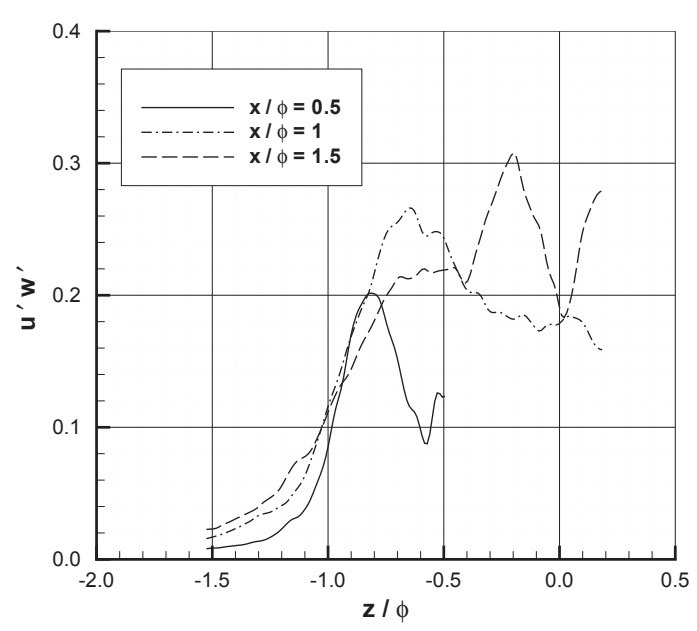

(c) $u^{\prime} w^{\prime}$ profiles.

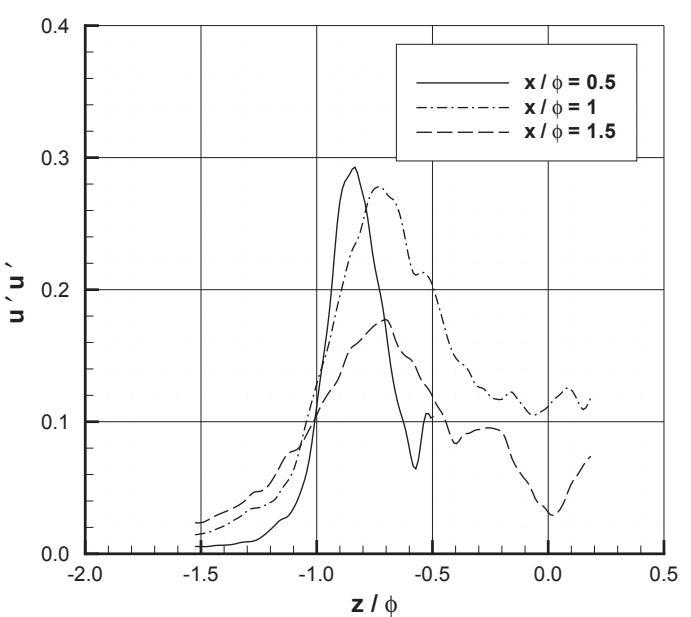

(b) $u^{\prime} u^{\prime}$ profiles.

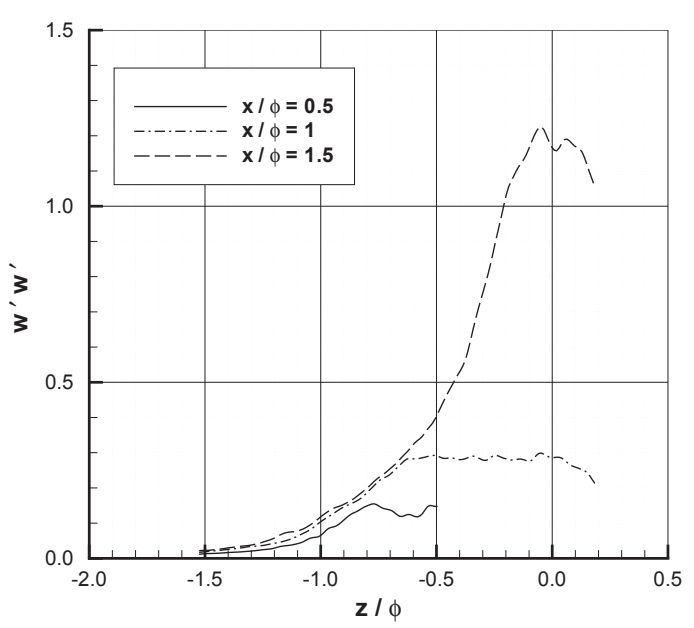

(d) $w^{\prime} w^{\prime}$ profiles

Figure 12. Profiles for HO configuration. 


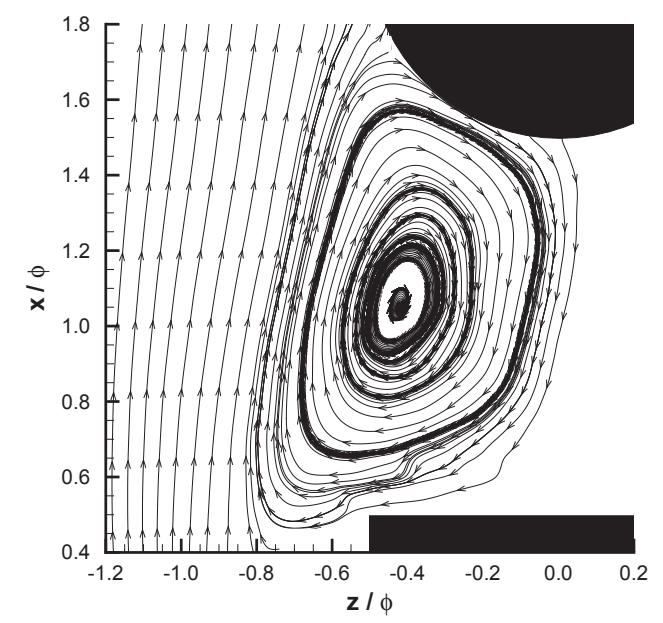

(a) Hardwall case.

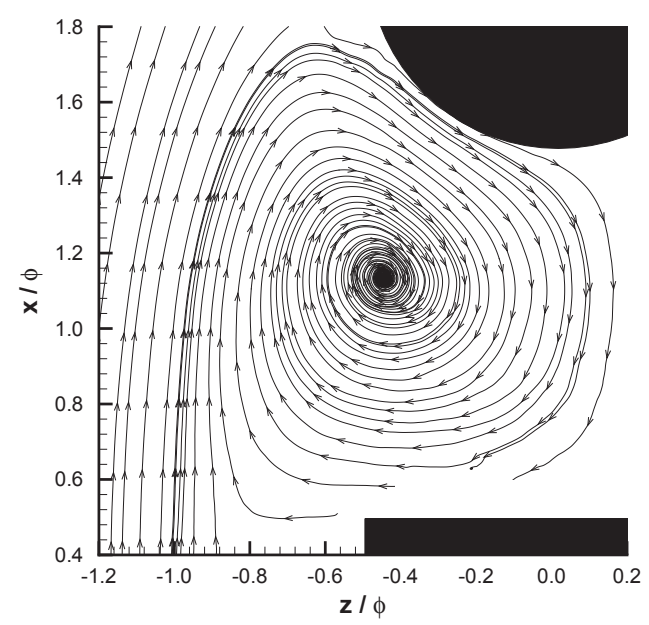

(b) Blowing. $C_{\mu}=1.3 \times 10^{-3}$.

Figure 13. Streamlines between H-beam and cylinder.

cylinder as shown in Figure 14(b). This altered the shape of the recirculation region in the wake of the H-beam.

The streamwise velocity profiles are shown in Figure 14(a) with blowing applied. This increased the length of the recirculation region between the H-beam and the cylinder. The gradient across the shear layer was increased with the application of blowing. The effect of blowing on the velocity fluctuations in the wake is shown in the Reynolds stress profiles shown in Figure 14(b). Due to the recirculation region being extended and the narrower shear layer, the streamwise fluctuations $\left(u^{\prime} u^{\prime}\right)$ are reduced at $x / \phi=1$ between the H-beam and the cylinder. At the leading-edge of the cylinder in the wake of the H-beam $(x / \phi=1.5)$, the $w^{\prime} w^{\prime}$ velocity fluctuations were significant for the hardwall case. This was caused by the strong wake shed from the H-beam. The effect of blowing on the cylinder was to steady the wake and to delay the reattachment on the surface of the cylinder. This reduced this stress term significantly as shown in Figure $14(\mathrm{c})$.

The turbulent stresses downstream of the cylinder are shown in Figure 14(d). The crossflow component, $w^{\prime} w^{\prime}$ is dominant due to the large unsteady wake behind the H-beam. With the application of blowing the peak along the centerline is reduced. Therefore not only was the flow between the H-beam and cylinder, but also the flow downstream of the cylinder modified. The unsteady velocity fluctuations were greatly reduced both upstream and downstream of the cylinder. These changes in the aerodynamic flow resulted in large reductions in the freefield acoustics.

\section{Free-field acoustic measurements}

The free-field acoustic measurements for the HO configuration are shown in Figure 15(a) for Plate 1. A large broadband noise reduction was achieved with the application of blowing. However, at frequencies above a Strouhal number of approximately 2 increasing the flow rate resulted in less reductions. This was due to the loud blowing noise that was produced and its increased bandwidth and magnitude at the higher flow rates. The high frequency additional noise with the perforated plate is centered around a Strouhal number of 30 . The next Section will deal with this blowing noise and its implications and in particular the atmospheric attenuation of this noise.

The noise reductions integrated over frequency ranges are shown in Figure 15(b). The largest reduction was centered around a Strouhal number of 0.8. The peak reduction was $13.5 \mathrm{~dB}$. From a Strouhal number range $0.05<S t<6.3$, the average noise reduction was $4.3 \mathrm{~dB}$. The use of blowing on the downstream cylinder was effective at reducing the broadband interaction noise.

The delaying of the reattachment of the shear layer on the downstream cylinder profoundly modified the 


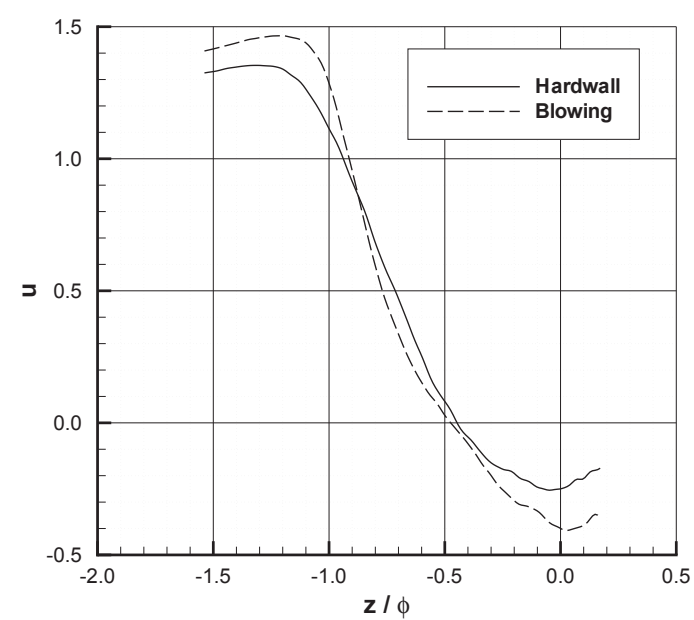

(a) $u$ velocity profiles at $x / \phi=1$.

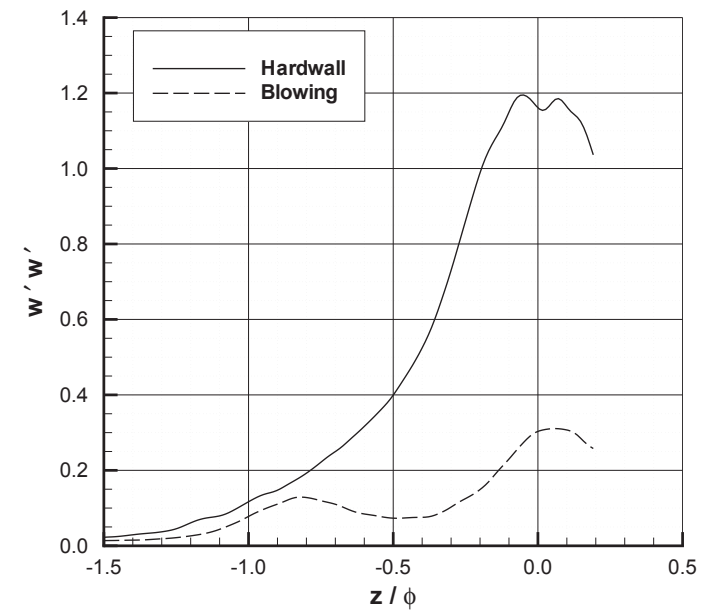

(c) $w^{\prime} w^{\prime}$ profiles at $x / \phi=1.5$

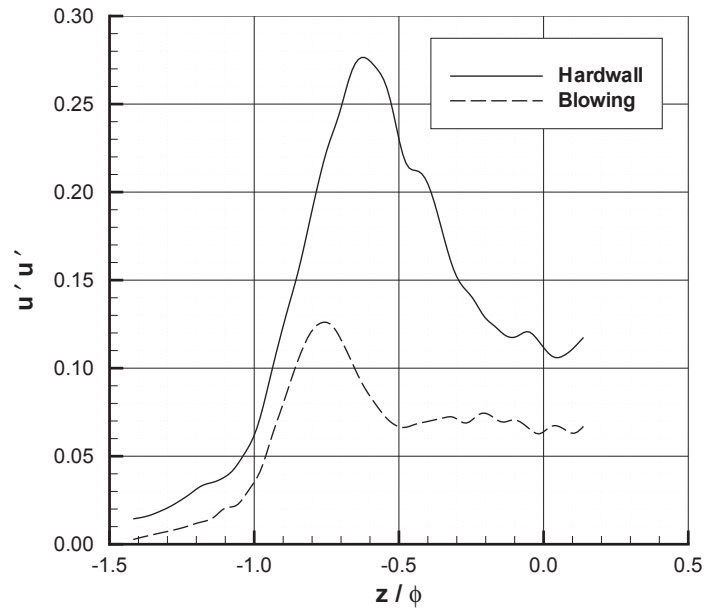

(b) $u^{\prime} u^{\prime}$ profiles at $x / \phi=1$.

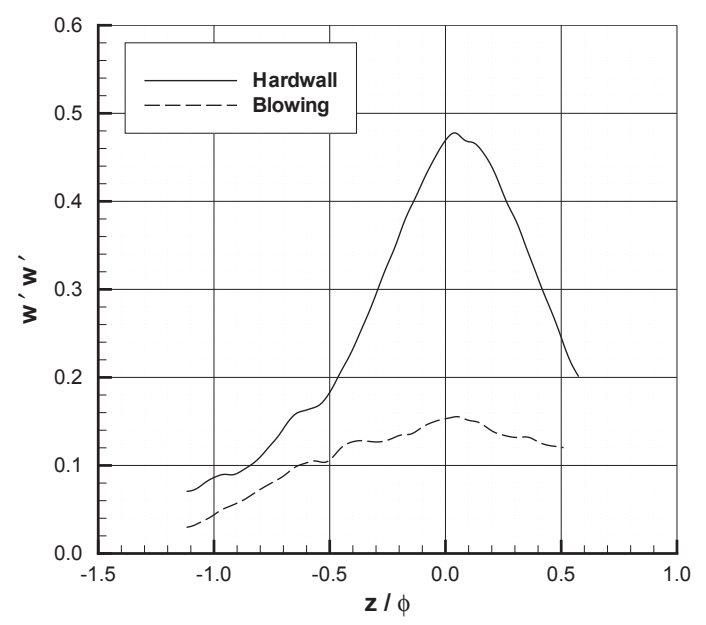

(d) $w^{\prime} w^{\prime}$ profiles at $x / \phi=2.5$.

Figure 14. Profiles for HO configuration behind cylinder. $C_{\mu}=1.7 \times 10^{-3}$.

flow between the two components and also downstream of the cylinder. The reductions were achieved by eliminating the strong cross flow between the two components. A similar reduction in interaction noise could also potentially achieved by a splitter plate between the two components to prevent the strong crossflow.

\section{Blowing System Noise}

The additional noise that arises from blowing is contributed to by many factors. In the application of noise reduction, the additional system noise is an important factor to determine and to minimise. The noise transmitted from the pump to the model is shown in Figure 16 and was above $1 \mathrm{kHz}$.

The noise from the settling tank that was delivered to the cylinder model is shown in Figure 16. The major noise was produced by the cross-drilled pipes that distributed the air within the plenum chambers of the cylinder model. This noise was centered around a frequency of $12 \mathrm{kHz}$. Since the plenum chambers were covered by perforated plates with two different pore diameters, the noise transmitted from the cross-drilled pipes to the free-field was greatly reduced. As previously shown the sintered plate (Plate 2) was effective at 


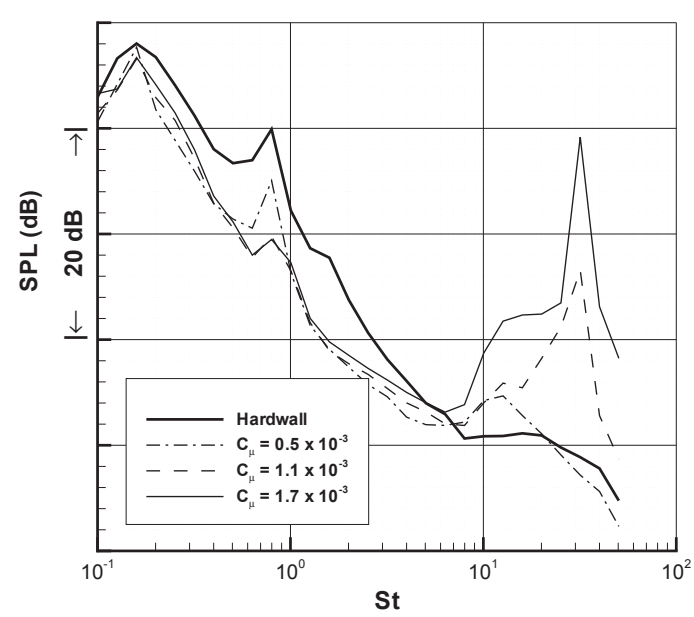

(a) HO noise with perforated plate.

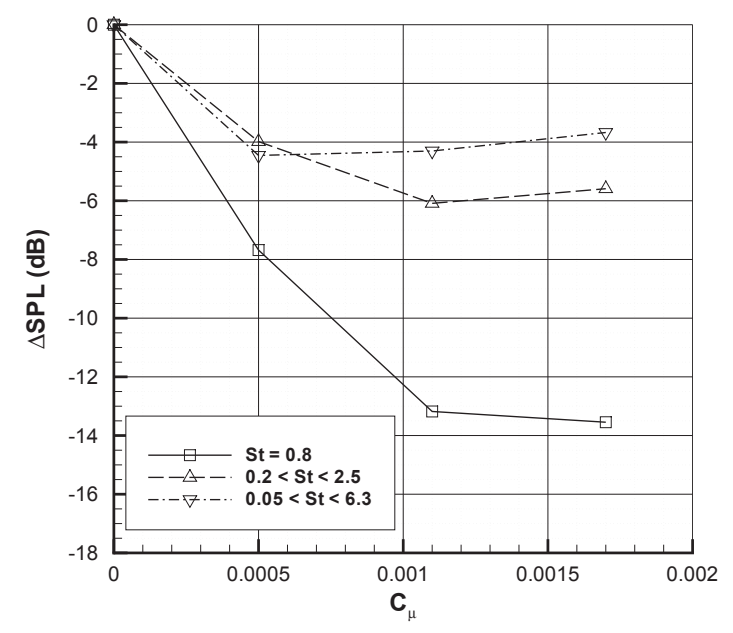

(b) Integrated noise reductions.

Figure 15. Free-field acoustic measurements for HO configuration. $r / \phi=21.4$ and $\psi=103$ deg.

shielding the majority of the system noise. There was an additional noise source from the blowing air passing through the pores of the perforated plates. However, the benefit of reducing the transmitted cross-drilled pipe noise was significantly more.

The acoustic measurements shown in Figure 16 were made with no freestream velocity. As the aerodynamic noise generated by the model increased with the freestream velocity, the additional blowing noise was below the noise levels generated. In these experiments, at a Reynolds number of $2.7 \times 10^{5}$ and with Plate 2 , the blowing noise was below the aerodynamic noise at all but the highest flow rates. The frequency of the additional noise was centered around $12 \mathrm{kHz}$. Therefore the blowing noise was a high frequency phenomenon and was acted upon by atmospheric attenuation, which had implications for its effectiveness at propagating into the free-field. At a temperature of $20 \mathrm{deg}$. Celcius and a pressure of one atmosphere with a relative humidity of $50 \%$, the atmospheric absorption was approximately $0.03 \mathrm{~dB} / 100 \mathrm{~m}$ at a Strouhal number of 0.25 based on the formulae presented by Bass et al. ${ }^{27}$ The high frequency blowing noise was at a Strouhal

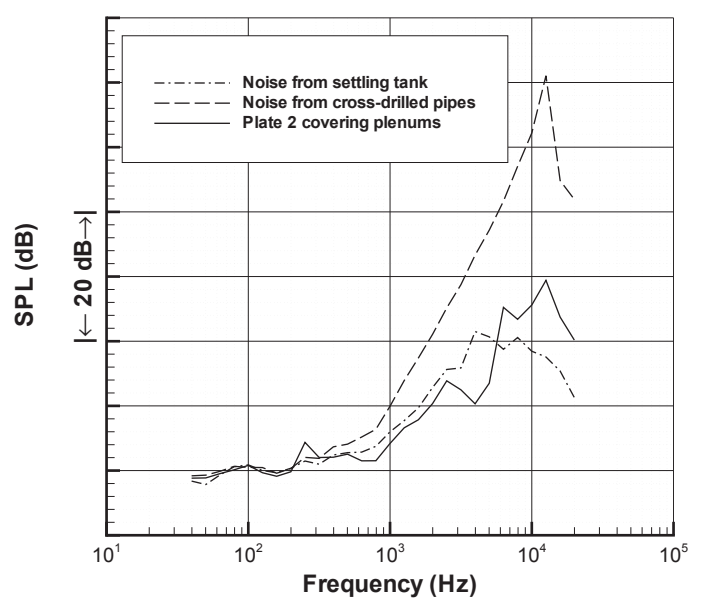

Figure 16. The additional noise due to blowing system. $V_{\infty}=0 \mathrm{~m} / \mathrm{s}$. 
number of 31 . The atmospheric attenuation at this frequency was approximately $30 \mathrm{~dB} / 100 \mathrm{~m}$. Therefore, the high frequency noise attenuated at a rate three orders of magnitude greater than the low frequencies where the majority of the aerodynamic noise from the model was generated.

\section{Conclusion}

The use of blowing to reduce interaction noise between two bluff body components was investigated. The components were a cylinder and an H-beam. The tandem configuration produced significantly more noise compared to the isolated components. The noise was also broadband in nature. Blowing was used to alter the wakes of the components and to modify the interaction noise that was generated by the wake of an upstream component impinging on a downstream component.

The noisiest configuration was the cylinder placed upstream of the H-beam ( $\mathrm{OH}$ configuration). The flowfield measurements showed that the peak velocity fluctuations were generated in the shear layers at the extremity of the wake of the cylinder. These velocity fluctuations upstream of the H-beam produced interaction noise. By applying blowing to the surface of the cylinder from 60 deg. to 150 deg., the streamwise growth of the shear layer thickness was suppressed. The streamwise velocity fluctuations in the wake of the cylinder upstream of the H-beam were approximately halved with the application of blowing at coefficient of $1.7 \times 10^{-3}$.

The effect of the flowfield changes on the free-field acoustic measurements was a broadband noise reduction. The peak reduction centered around a Strouhal number of 0.2 was $9.3 \mathrm{~dB}$ with Plate 2 applied at a blowing coefficient of $1.15 \times 10^{-3}$. The broadband noise reduction averaged over a Strouhal number range $0.05<S t<5\left(20 \mathrm{~Hz}<f<2 \mathrm{kHz}\right.$ at $\left.R e=2.7 \times 10^{5}\right)$ was $3.2 \mathrm{~dB}$. Therefore, the effect of modifying the wake of the cylinder with blowing was to produce a significant broadband reduction. Plate 2 with a small pore diameter was effective at eliminating the additional high frequency blowing noise at all but the highest flow rate.

The second configuration tested was the H-beam upstream of the cylinder (HO configuration). The mean flowfield was characterised by a recirculation region between the H-beam and the cylinder. The shear layer attached on the upwind face of the cylinder. Between the two components, there were strong crossflow velocity $(w)$ fluctuations caused by the strong wake downstream of the H-beam. The effect of blowing of the aerodynamic flowfield was to move the reattachment line of the shear layer downstream on the cylinder. This widened the recirculation region between the cylinder and the H-beam. The effect on the velocity fluctuations were to reduce the streamwise fluctuations. The most influence was a large reduction in the crossflow velocity fluctuations between the H-beam and the cylinder. This led to a large reduction in the interaction noise.

The farfield acoustic measurements showed a peak reduction of $13.5 \mathrm{~dB}$. The broadband noise reduction was $4.3 \mathrm{~dB}$ averaged over the frequency range $0.05<S t<6.3$ at a blowing coefficient of $1.1 \times 10^{-3}$. These measurements were made with Plate 1 . The lower crossflow velocity fluctuations between the H-beam and the cylinder was a large broadband reduction. There was additional high frequency noise especially with the largest flow rate.

The origin of most of the high frequency blowing noise was determined to be the cross-drilled pipes that fed the plenum chambers of the cylinder model. With Plate 2 the additional blowing noise was greatly reduced. Also since the additional blowing noise was high frequency, it was acted upon by atmospheric attenuation. At the typical atmospheric values that the measurements were made, the atmospheric attenuation of the blowing noise was approximately one thousand times greater than the low frequencies where the aerodynamic noise was generated.

The tandem components of a cylinder and an H-beam produced broadband interaction noise. Blowing applied through the perforated surface of the cylinder was effective at reducing the broadband interaction noise. Only relatively small blowing coefficients were required to achieve large reductions in the free-field acoustics. The velocity fluctuations measured in the wake of the components correlated well with the reductions in acoustics and provided an explanation for the flowfield changes responsible.

\section{Acknowledgements}

The research funding for this project was provided by Airbus. 


\section{References}

${ }^{1}$ Dobrynski, W., Chow, L. C., Guion, P., and Shields, D., "Research into Landing Gear Noise Reduction," AIAA Paper 2002-2409, 2002.

${ }^{2}$ Crighton, D. G., "Airframe Noise in Aeronautics of Flight Vehicles: Theory and Practice," NASA RP, Vol. 1: Noise Sources, No. 1258, 1991.

${ }^{3}$ Curle, N., "The Influence of Solid Boundaries upon Aerodynamic Sound," Proceedings of the Royal Society, Vol. A231, 1955, pp. 505-514.

${ }^{4}$ Dobrynski, W., Chow, L. C., Guion, P., and Shields, D., "A European Study on Landing Gear Airframe Noise Sources," AIAA Paper 2000-1971, 2000.

${ }^{5}$ Heller, H. H. and Dobrynski, W. M., "Sound Radiation from Aircraft Wheel-Well/Landing Gear Configurations," Journal of Aircraft, Vol. 14, No. 2, 1977, pp. 768-774.

${ }^{6}$ Howe, M. S., Theory of Vortex Sound, Cambridge University Press, 1st ed., 2002.

${ }^{7}$ Gad-el-Hak, M., "Modern Developments in Flow Control," Applied Mechanics Reviews, Vol. 49, 1996, pp. 365-379.

${ }^{8}$ Anders, S., Sellers III, W. and Washburn, A. , "Active Flow Control Activities at NASA Langely," AIAA Paper 20042623, 2004.

${ }^{9}$ Bower, W. and Kibens, V., "An Overview of Active Flow Control Applications at the Boeing Company," AIAA Paper 2004-2624, 2004.

${ }^{10}$ Jacob, M. C., Boudet, J., Casalino, D., and Michard, M., "A Rod-Airfoil Experiment as Benchmark for Broadband Noise Modeling," Theoretical and Computational Fluid Dynamics, Vol. 19, 2005, pp. 171-196.

${ }^{11}$ Siller, H. A., Jacob, M. C., and Michel, U., "Flow and Noise Modification by Suction and Blowing on a Rod-Airfoil Configuration," AIAA Paper 2005-3029, 2005.

${ }^{12}$ Fransson, J. H. M., Koniecznyk, P., and Alfredsson, P. H., "Flow around a Porous Cylinder Subject to Continuous Blowing or Suction," Journal of Fluids and Structures, Vol. 19, 2004, pp. 1031-1048.

${ }^{13}$ Mathelin, L., Bataille, F., and Lallemand, A., "The Effect of Uniform Blowing on the Flow Past a Circular Cylinder," Journal of Fluids Engineering, Vol. 124, 2002, pp. 452-464.

${ }^{14}$ Mathelin, L., Bataille, F., and Lallemand, A., "Near Wake of a Circular Cylinder Submitted to Blowing Parts 1-2," Int. J. Heat Mass Transf., Vol. 44, No. 19, 2000, pp. 3701-3719.

${ }^{15}$ Leitch, T. A., Saunders, C. A., and Ng, W. F., "Reduction of Unsteady Stator-Rotor Interaction Using Trailing Edge Blowing," Journal of Sound and Vibration, Vol. 235, No. 2, 2000, pp. 235-245.

${ }^{16}$ Zdravkovich, M. M., "Flow Induced Oscillations of Two Interfering Circular Cylinders," Journal of Sound and Vibration, Vol. 4, 1985, pp. 511-521.

${ }^{17}$ Lockard, D. P., Choudhari, M. M., Khorrami, M. R., Neuhart, D. H., Hutcheson, F. V., Brooks, T. F., and Stead, D. J., "Aeroacoustic Simulations of Tandem Cylinders with Subcritical Spacing," AIAA Paper 2006-2862, 2008.

${ }^{18}$ Lockard, D. P., Khorrami, M. R., Choudhari, M. M., Hutcheson, F. V., and Brooks, T. F., "Tandem Cylinder Noise Predictions," AIAA Paper 2007-3450, 2007.

${ }^{19}$ Lyn, D. A. and Rodi, W., "The Flapping Shear Layer Formed by Flow Separation from the Forward Corner of a Square Cylinder," Journal of Fluid Mechanics, Vol. 267, 1994, pp. 353-376.

${ }^{20}$ Lockard, D. P., Khorrami, M. R., and Li, F., "High Resolution Calculation of a Simplified Landing Gear," AIAA Paper 2004-2887, 2004.

${ }^{21}$ Lazos, B. S., "Mean Flow Features around the Inline Wheels of a Four-Wheel Landing Gear," AIAA Journal, Vol. 40, No. 2, 2002, pp. 193-198.

${ }^{22}$ Lazos, B., "Surface Topology on the Wheels of a Generic Four-Wheel Landing Gear," AIAA Journal, Vol. 40, No. 12, 2002, pp. 2402-2411.

${ }^{23}$ Piet, J.-F., Chow, L. C., Laporte, F., and Remy, H., "Flight Test Investigation of High-Lift Devices and Landing Gear Modifications to Achieve Airframe Noise Reduction," European Congress on Computational Methods in Applied Sciences and Engineering (ECCOMAS), Jyvskyl, Sweden, $24-28$ July 2004.

${ }^{24}$ Lockard, D. P. and Lilley, G. M., "The Airframe Noise Reduction Challenge," NASA/TM-2004-213013, 2004.

${ }^{25}$ Bearman, P. W., "On Vortex Shedding from a Circular Cylinder in the Critical Reynolds Number Regime," Journal of Fluid Mechanics, Vol. 37, No. 3, 1969, pp. 577-585.

${ }^{26}$ Djilali, N. and Gartshore, I. S., "Turbulent Flow around a Bluff Rectangular Plate. Part 1: Experimental Investigation," Journal of Fluids Engineering, Vol. 113, 1991, pp. 51-59.

${ }^{27}$ Bass, H. E., Sutherland, L. C., Zuckerwar, A. J., Blackstock, D. T., and Hester, D. M., "Atmospheric Absorption of Sound: Further Developments," Journal of the Acoustical Society of America, Vol. 91, No. 1, 1995, pp. 680-683. 